\title{
Cuando no hablamos de integración: análisis de la imagen del alumnado "inmigrante" en la prensa en España ${ }^{1}$
}

\author{
Francisco Javier GARCÍA CASTAÑO \\ Universidad de Granada \\ fjgarcía@ugr.es \\ Antolín GranAdos MarTíNEZ \\ Universidad de Granada \\ granados@ugr.es \\ Antonia Olmos Alcaraz \\ Universidad de Granada \\ antonia@ugr.es \\ Raquel MarTínez CHICÓN \\ Universidad de Granada \\ raquelchicon@ugr.es
}

Recibido: 31 de diciembre de 2013

Aceptado: 28 de mayo de 2014

\section{Resumen}

La mayor parte de los estudios muestran que los medios de comunicación, la prensa en particular, desempeñan un papel fundamental en la reproducción del discurso sobre la inmigración. Dicho discurso está centrado en resaltar los problemas que causan en la sociedad de acogida, o las dificultades con las que se encuentran, y no en los aportes que puede tener la integración. Pero ¿qué sucede cuando localizamos el fenómeno migratorio en un contexto concreto? ¿se reproducen los discursos existentes sobre el fenómeno migratorio en general en la imagen que se ofrece sobre el alumnado de nacionalidad extranjera en la prensa en España? A partir de nuestros análisis, hemos podido observar cómo existe en este ámbito una reproducción de los discursos existentes sobre la inmigración en general. A la reflexión sobre estas cuestiones dedicamos este artículo.

Palabras clave: Discursos, imagen, inmigración, escolares, medios de comunicación, integración

\section{When We Are not Talking about Integration: An Analysis of the Portrayal of "Immigrant" School Population in the Spanish Press}

\begin{abstract}
Most Studies show that Media, and particularly the Press, have an essential role in reproducing the discourse of foreign immigration. This discourse focuses on highlighting the problems caused by immigrants during their integration process, or on the difficulties they have to face and which are recognized

1 Este artículo es resultado de algunas investigaciones ya concluidas, así como de un proyecto iniciado recientemente en el marco del Plan Nacional de $\mathrm{I}+\mathrm{D}+\mathrm{i}$ y que pretende estudiar las trayectorias escolares del alumnado "extranjero" en comparación con el alumnado autóctono [Éxitos y fracasos escolares. Trayectorias socioculturales de "inmigrantes extranjeros" y escolares autóctonos en el sistema educativo andaluz (CSO2010-22154-C03-01)]. Agradecemos al Ministerio de Ciencia e Innovación el apoyo a dicha investigación. Igualmente, parte del texto contiene unos primeros resultados de la investigación en marcha "Discursos de extranjería en los medios de comunicación andaluces: la construcción discursiva y visual de la nueva Andalucía". En este segundo caso se trata de un Proyecto de Excelencia de la Junta de Andalucía (TIC-6517) de la convocatoria de 2010.
\end{abstract}


within their diversity, and not on the acknowledgment of the benefits that the integration may imply. However, what happens when we identify the issue of immigration within a specific context? Are the existing discourses on the issue of migration reproduced in general through the portrayal of foreign school population offered by the Spanish press? From our analysis, we have been able to identify that there is a particular representation of the discourses on the issue of immigration. In the following pages, we intend to reflect and analyse such matters.

Keywords: Discourses, portrayal, immigration, school children, Media, integration

\section{Referencia normalizada}

GARCÍA CASTAÑO, Francisco Javier; GRANADOS MARTÍNEZ, Antolín; OLMOS ALCARAZ, Antonia; y MARTÍNEZ CHICÓN, Raquel (2014): "Cuando no hablamos de integración: análisis de la imagen del alumnado "inmigrante" en la prensa en España". Estudios sobre el Mensaje Periodístico. Vol. 20, Núm. 2 (julio-diciembre), págs.: 1081-1101. Madrid, Servicio de Publicaciones de la Universidad Complutense.

Sumario: 1. Consideraciones previas. 2. Sobre inmigración, integración y prensa en España. 3. El alumnado de nacionalidad extranjera en la prensa en España: de avalanchas, guetos y fracaso escolar; 3.1. Sobre cómo conseguir que "uno de cada ocho" parezcan una avalancha; 3.2. Instrucciones para construir un gueto; 3.3. Receta para culpar al inmigrante del fracaso escolar de la escuela en España. 4. Reflexiones finales. 5. Referencias bibliográficas.

\section{Consideraciones previas}

Los años que han marcado el cambio de siglo, los tres últimos lustros, han transformado la estructura poblacional en España con situaciones difíciles de explicar y de comprender si se elude o se obvia el papel de la inmigración extranjera. Así, por ejemplo, siendo uno de los países con menor tasa de natalidad del mundo identificado como "desarrollado", su población no ha dejado de crecer numéricamente. Esta aparente paradoja se explica en parte por la presencia de esta población, que a día de hoy suman 5.503.977 millones (algo menos del 12\% de la población total)². Por su parte, la imagen que se ha formado durante todo este tiempo de la inmigración extranjera en el país es calificable de todo menos de favorable e integradora. Muy al contrario se sigue confirmando y acentuando una imagen simplista, estereotipada y, en el mejor de los casos, asimiladora de la diversidad representada por la inmigración, empeñada en convertirla en diferencia insalvable. Se podría decir que la sociedad en España se niega a asumir la realidad de la inmigración como una realidad consustancial a las dinámicas del cambio social propio de sociedades globalizadas, multiétnicas y multiculturales. Los medios de comunicación, en particular la prensa, además de otras instancias de socialización -la escuela, la familia o los partidos políticos- son, en buena medida, corresponsables de dicha percepción.

Es sabido que podríamos iniciar un debate epistemológico imposible de agotar en las páginas que conforman este texto sobre qué es la integración y qué no lo es. No es nuestro objeto. No obstante sí es preciso exponer cómo la entendemos nosotros en este trabajo. La integración no es solamente una vía intermedia entre inserción y asimilación, puesto que si así fuera incluiría al nuevo miembro que llega sin transformarlo radicalmente. La integración obliga a una reflexión más compleja y matizada sobre lo que es la sociedad:

${ }^{2}$ Datos del Instituto Nacional de Estadística, a 30 de enero de 2013. 
Obliga a considerar toda sociedad como aquella forma de identidad que permanece al tiempo que se modifica por la vitalidad de (las) nuevas aportaciones y de sucesivas redefiniciones. Las generaciones que acceden a la edad adulta -aportación que no es ni automática, ni natural- pero también la inmigración son constitutivas de una identidad dinámica. Estas aportaciones representan tanto fuente de riqueza como fuente de problemas $^{3}$ (Grange, 2005: 43).

La integración, por lo tanto, es algo que afecta a toda la sociedad, fruto de aportaciones y redefiniciones continuas, y generadora al mismo tiempo de situaciones tanto enriquecedoras como problemáticas. No queremos alargar en demasía este debate, ni introducir en el mismo más conceptos que lo complejicen, pero no podemos dejar de mencionar a la interculturalidad, como paradigma que pretende conseguir esa integración. A este respecto, y en concordancia con la idea que acabamos de comentar, nos hacemos eco de los aportes que realiza $\mathrm{C}$. Walsh sobre lo que denomina "interculturalidad crítica": una noción de la misma como algo que va más allá del respeto, la tolerancia y el reconocimiento a la diversidad; como un proyecto socio-político de construcción de sociedades, relaciones y condiciones de vida nuevas; como una perspectiva que es consciente de que las relaciones de intercambio pueden ser tanto de igualdad como de desigualdad y que no minimiza los problemas que subyacen a dichas relaciones (Walsh, 2010).

\section{Sobre inmigración, integración y prensa en España}

Y ¿qué encontramos de todo ello en la prensa en España? Las migraciones son un fenómeno mediático de primera magnitud. Con ello queremos decir que una realidad que es múltiple, plural, diversa y, por todo ello, compleja para las ciencias sociales, ha sido transformada y transmutada por intermediación de los medios de comunicación -sus intérpretes- a una realidad consumible y opinable desde su reducción atemporal (ahistórica), caricaturesca, estereotipada y anecdótica. La reflexión vale, obviamente, para cualquier país europeo. Como tal fenómeno mediático, su traslación en la opinión pública tiene efectos contundentes: el número de noticias en prensa, radio y televisión, la frecuencia con la que aparecen y, sobre todo, el tratamiento al que son sometidas por cada uno de los medios, tienen el efecto de generar en la opinión de los lectores, radioyentes y telespectadores, preocupación, prevención, recelo, prejuicios, desconfianza, temor y rechazo; esto es, todo menos aquello que pudiera facilitar el acercamiento, el contacto, la confianza, la curiosidad natural por el mejor conocimiento de quienes comparten sus vidas en España: integración e interculturalidad. La investigación demuestra, por ejemplo, que uno de los motivos más aludidos para explicar por qué los españoles consideran la inmigración como un fenómeno problemático y problematizador se encuentra en el tratamiento que le confieren los medios de comunicación [Bañón, 2007; Casero, 2005, 2007; Granados, 1998, 2006; Igartua y Muñiz, 2007 (eds.); Lario, 2006; Lorite, 2004; Retis, 2006; Santamaría, 2002, y muchos otros]. De ahí que las agendas de los partidos políticos y las encuestas de opinión -catalizadores de los discursos vertidos en los medios- sean un buen reflejo de la per-

${ }^{3}$ La traducción es nuestra. 
cepción que se tiene del fenómeno. La mayor parte de los estudios anteriormente citados muestran que los medios en general, y la prensa en particular, desempeñan un papel fundamental en la reproducción del discurso sobre la inmigración económica extranjera; discurso centrado en resaltar los problemas que causan en la sociedad de acogida, o las dificultades con las que se encuentran para ser aceptados y reconocidos en su diversidad, y no los aportes que puede tener la integración de poblaciones diversas ${ }^{4}$.

Pero ¿qué sucede cuando localizamos el fenómeno migratorio en un contexto concreto? Es decir ¿qué discursos específicos podemos identificar cuando, por ejemplo dado que es la intención de este capítulo- observamos el binomio inmigración-escuela en la prensa en España? O dicho de otra manera ¿se reproducen los discursos existentes sobre el fenómeno migratorio en general en la imagen que se ofrece sobre el alumnado de nacionalidad extranjera ${ }^{5}$ en la prensa en España? A partir de nuestros análisis hemos podido observar cómo la llegada de la población extranjera (inmigrante) a las escuela en España -con sus consiguientes aportaciones- está siendo presentada por la prensa -y por extensión por todos los medios de comunicación- más cómo un problema que como una riqueza, porque está evitando en buena medida, en nuestra opinión, que la sociedad se vea impelida a reflexionar de manera dinámica acerca de dichas aportaciones. Existiría, por lo tanto, en este ámbito una reproducción de los discursos existentes sobre la inmigración como fenómeno en general. En las líneas que siguen nos disponemos a analizar y reflexionar sobre dichas cuestiones.

\section{El alumnado de nacionalidad extranjera en la prensa en España: de avalan- chas, guetos y fracaso escolar}

Antes de comenzar con nuestros análisis queremos avanzar una serie de datos sobre los lugares comunes a propósito de la inmigración en la prensa escrita en España. El objetivo, además de contextualizar las observaciones posteriores, es arrojar luz sobre los procesos de integración a partir de la información relativa al modo en que son reconocidos, juzgados, retratados y, en función de todo ello, aceptados o rechazados, los extranjeros (inmigrantes) en el país.

${ }^{4}$ En paralelo a las labores llevadas a cabo en la investigación han ido surgiendo a lo largo de los noventa del siglo pasado códigos éticos, estatutos de redacción, convenios colectivos o libros de estilo que procuran una especial sensibilidad hacia las informaciones u opiniones de contenido discriminatorio por razón de raza, sexo, moral sexual, lengua, religión u origen nacional o social.

5 Aunque en el título del este texto hemos aludido al alumnado "inmigrante" podrá verse que en el resto del texto nos limitaremos al uso de los términos de alumnado de nacionalidad extranjera. Queremos plantear nuestras reservas a seguir utilizando algunos calificativos en la construcción de "sujetos de investigación". No dudamos del uso social de tales términos y de la normalidad con la que parecen usarse en la escuela, pero queremos objetar a la necesidad de seguir utilizándolo en la investigación por lo poco que aportan analíticamente y por las consecuencias esencialistas que suponen. Por nuestra parte haremos referencia a alumnado de nacionalidad extranjera o/y inmigrado (cuando consideremos que debemos resaltar esta faceta del mismo); e insistiremos en el uso entrecomillado de los términos "inmigrantes" y "extranjeros" cuando sean usados desde el discurso emic o para hacer referencia al mismo. 
Para ello tomamos los datos que hemos obtenido del Centro de Estudios y Documentación sobre el Racismo (Mugak), en consulta realizada en su página $W^{6} b^{6}$, y las conclusiones que extraemos al respecto pueden resumirse como siguen:

1. La mayor parte de las informaciones recogidas (el 37,8\%) hacen muestra de un tipo de inmigración que llega a España a través del mar. En ello vemos que el mensaje que se está trasladando a la ciudadanía es que toda la inmigración llega a través del Estrecho. Además, la sensación de "invasión" (pateras, muertes y áreas de detención) y su consiguiente efecto de control y defensa (acuerdos con terceros países, regulación del proceso migratorio y centros de internamiento), aparecen de manera destacada entre el conjunto de las informaciones. Así, un inadecuado manejo de cifras y de fuentes tiene un efecto perceptivo de fenómeno masivo. En tales condiciones, es dudoso que el lector de ese tipo de informaciones acabe haciéndose una idea cabal del número de personas procedentes del continente africano -y de otros lugares-, pero es seguro que las informaciones que lee contribuyan a hacerle sentirse comprensivo con las medidas de control de fronteras, las detenciones y las deportaciones. Los medios, la prensa en esta ocasión, están contribuyendo con las formas en que notician el fenómeno a la legitimación de una política migratoria de carácter represivo, opresivo y abusivo. Además lo que el lector de los titulares probablemente nunca sabrá es que el grueso de la inmigración en situación irregular -y no- no llega en pateras o en cayucos, sino que entra por los aeropuertos y por las fronteras terrestres?

2. En orden de importancia numérica, en segundo lugar, encontramos noticias que hacen referencia a regularizaciones, normalizaciones... y normativa de extranjería en su conjunto. Siendo como es uno de los problemas más importantes que tiene la so-

6 El corpus de unidades informativas analizadas ha sido extraído del vaciado que Mugak hace de El País, El Mundo, ABC y La Vanguardia. Los tipos considerados han sido Editorial, Artículo/Columna, Información, Entrevista, Carta y "Otros". Y el periodo seleccionado comprende de 1 de junio y a 30 de septiembre de 2006. Todo ello puede consultarse en http://medios.mugak.eu/Mugak.

7 De hecho, según datos del Instituto Nacional de Estadística, a 1 de enero de 2005, la población empadronada y originaria de toda África, representaba en el período analizado por nosotros (recuérdese: 1 de junio y el 30 de septiembre de 2006) el 19,2\% de la población extranjera, mientras que la población empadronada y originaria de América del Sur, América Central y Caribe representaba justo el doble: el 38,3\%. Por su parte, los datos provisionales sobre Población Extranjera empadronada, a 1 de enero de 2006, arrojaban los siguientes porcentajes: el 16,6\% de la población extranjera era originaria de países europeos no miembros de la Unión Europea de los 25 (UE-25), contra el 13,8\% de la población de origen marroquí, y el $5 \%$ del resto de las poblaciones inmigrantes originarias del resto de África. Así pues, los inmigrantes originarios de países europeos no son "visibles" para los medios de comunicación; no son "espectáculo mediático", no alteran las pulsiones xenófobas (en este caso, el "otro" es el "nosotros" blanco y cristiano), no vienen a delinquir, no vienen a invadir "nuestro" territorio ni a vivir a costa de "nuestro" estado de bienestar. Tales datos no coinciden ni con las informaciones que publican los periódicos ni con la opinión que tienen los españoles respecto de la procedencia de los inmigrantes, lo que además no creemos que responda a una lógica azarosa y casual. 
ciedad en España, en opinión manifestada en las encuestas, vemos cómo además se ha convertido en un problema de debate social y, sobre todo, político. Por su rentabilidad electoral, la inmigración se convierte cada vez que hay elecciones -municipales, autonómicas o nacionales- en un asunto político de primer interés que es altamente noticiado. El "miedo hacia el extranjero" se ha impuesto como tema de relevancia pública y, a nivel estatal, ha obligado a cambios en la agenda política e institucional de los últimos gobiernos con medidas de carácter preventivo mediante acuerdos y convenios con los países desde los que salen pateras y cayucos (Marruecos, Mauritania, Senegal, Gambia y Guinea Bissau, entre otros). El cambio de rumbo de la política migratoria, en los discursos y en las acciones del gobierno, es especialmente sensible hacia posiciones de más control y contención de los flujos migratorios.

3. En tercer lugar mencionaríamos las informaciones que refieren al inmigrante desde el punto de vista delictivo que, pese a ser numéricamente poco relevantes, producen un efecto que alimenta y justifica todo tipo de prevenciones y de medidas electoralmente seductivas. Al recoger con literalidad declaraciones efectuadas por responsables políticos y policiales -fuentes principales a las que acuden los periodistas para documentar sus informaciones-, pero a menudo descontextualizándolas, dichas informaciones reflejan un servilismo informativo o una complicidad inquietante cuando, por ejemplo, hacen suya la equiparación del inmigrante ilegal con terroristas, delincuentes y narcotraficantes. Sea como causante del delito o como objeto del mismo, su presencia en titulares, identificado por su condición de inmigrante y/o extranjero (nacionalidad, origen geográfico, etc.) le aseguran un lugar relevante en los esquemas y guiones cognitivos del lector de estos titulares, para quien el inmigrante aparece relacionado, en última instancia, con hechos considerados problemáticos, conflictivos o delictivos.

4. Queremos también significar por su carácter novedoso, pero también por representar el 5,6\% del total de las informaciones publicadas en los cuatro periódicos analizados, aquellas que evidencian los conflictos entre las distintas administraciones del Estado a la hora de gestionar la inmigración extranjera originaria, sobre todo, de África. Especialmente los conflictos entre el Gobierno Central y las Comunidades Autónomas que son receptoras principales de las llegadas de inmigrantes en pateras o en cayucos. Al ser un fenómeno directamente gestionado por el gobierno central que deja sin competencias plenas a los gobiernos autonómicos, la inmigración extranjera, sobre todo la que se produce en condiciones de irregularidad, se ha convertido en uno de los focos de conflicto político más viscerales, principalmente cuando los gobiernos autonómicos de signo político contrario al central la utilizan como arma arrojadiza para socavar su gestión'.

${ }^{8}$ Aunque pueda tratarse este de un tema poco usual en los medios de comunicación, en el discurso político "la cuestión de las competencias" es central y transversal al abordar cualquier temática relacionada con la inmigración, sobre todo en las comunidades donde el gobierno no es del mismo signo político que el gobierno central, aunque no solo. Puede consultarse el trabajo realizado sobre discurso parlamentario por Olmos Alcaraz (2009) para un análisis más detallado a este respecto. 
5. Y, finalmente, aparecen en la prensa informaciones que podemos considerar relativas a los espacios sociales de relación, de convivencia y de aceptación para la integración - es decir, unidades informativas que hablan de educación, trabajo, vivienda y salud, principalmente-. Este corpus supone el $4,8 \%$ del total de las informaciones publicadas en los cuatro periódicos considerados. Son de atención informativa cuando los periódicos relatan las condiciones infrahumanas en las que se desenvuelven en general los inmigrantes: viven en chabolas y barrios marginales de las grandes ciudades, hacinados en espacios reducidos sin unas mínimas condiciones de higiene, con trabajos precarios en la economía sumergida o en sectores productivos que los españoles no están dispuestos a ocupar, en condiciones de semi-esclavitud por los bajos salarios que perciben y por las pocas o ningunas garantías de seguridad física o de respeto hacia sus derechos como trabajadores (Martínez, 2005). Esto se debe probablemente a que es en estos dos aspectos de su relación con la población autóctona donde el inmigrante se hace más visible y, por tanto, "problemático": sus convecinos aceptan mal su presencia, sus "iguales" en el trabajo los perciben como competidores en un país en el que el paro y la crisis se está cebando con los más débiles. Por su parte, las noticias que relacionan al inmigrante con la educación -o con la salud- son muy escasas en los cuatro periódicos en el periodo considerados. Los datos de escolarización de hijos de inmigrantes, los encuentros, cursos y jornadas sobre educación intercultural, las dificultades del alumnado de padres inmigrantes para su integración en el sistema educativo, y casos concretos de concentración de escolares hijos de inmigrantes en centros públicos que corren el riesgo de convertirse en guetos son principalmente las temáticas de los titulares que podemos encontrar al respecto.

Recapitulando lo dicho hasta ahora, la prensa en España ofrece una imagen sobre la inmigración relativa principalmente a un tipo específico, la inmigración que se produce de manera irregular, procedente de países africanos; nos muestra nuestra preocupación por la aplicación de la normativa de extranjería a este fenómeno -lo cual enfatiza la idea de algo que ha de ser regulado constantemente, controlado, pautado, gestionado, intervenido por las fuerzas de seguridad-; sigue mostrándonos, aunque no en exclusiva, a una inmigración relacionada con lo delictivo; y sigue sin noticiar lo suficiente los espacios convivenciales entre autóctonos y foráneos: y cuando lo hace, es para mostrar dificultades, miserias, pobreza, paternalismo y exotismo. Veamos a continuación un análisis más detallado de las informaciones recogidas sobre inmigración y educación.

Ya hemos comentado cómo el porcentaje de informaciones que muestran el fenómeno migratorio relacionado con el ámbito educativo (quizá uno de los más importantes ámbitos/contextos de integración entre poblaciones diversas) son relativamente escasas en relación a otro tipo de unidades informativas. Este hecho en sí ya es bastante revelador. Tomando una muestra un poco más amplia ${ }^{9}$ de unidades informativas incluso podemos establecer una periodicidad estimada de aparición de esta temática

${ }^{9}$ En esta ocasión estamos considerando dos años de informaciones publicadas en El País, El Mundo, El Periódico de Cataluña y La Vanguardia (desde 1 de enero de 2006 a 31 de diciembre de 2007). Todo ello, de nuevo, a partir del vaciado de noticias que realiza Mugak. 
en prensa. Siendo así hemos observado cómo, si bien, en la prensa aparecen una media de tres noticas que hablan de inmigración al día, las notas las relativas a inmigracióneducación sólo aparecen una cada tres días. Y ¿de qué hablan esas unidades información si, como ya hemos mencionado, no hablan de integración? Pues, como adelantamos en el título de este epígrafe, principalmente de avalanchas, guetos y fracaso escolar (temáticas, eso sí, transversalizadas por otras cuestiones que iremos comentando). Veamos cómo ${ }^{10}$.

\subsection{Sobre cómo conseguir que "uno de cada ocho" parezcan una avalancha}

Nos estamos refiriendo, por supuesto, a alumnos extranjeros -los inmigrantes son más difíciles de contabilizar...-. Y lo primero que habría que preguntarse es "uno de cada ocho" ¿con respecto a qué? ¿en relación a cuánto? Y después, si esto ¿es mucho, poco? La prensa lo tiene bastante claro: se trata de una avalancha. Valga el siguiente ejemplo de un periódico que no es nada sospechoso por el rigor con el que comunica sus informaciones y por una deontología ética especialmente estricta con el tratamiento de la inmigración:

[Titular/Noticia] Avalancha en una zona bilingüe

[Primer párrafo/Cuerpo noticia] La avalancha inmigratoria en Baleares que se evidencia en el aumento de la población del 4,4\% en 2002 ha disparado el segmento de alumnos extranjeros hasta del $8,7 \%$ en este curso.

[El Pais: 29/09/2003]

${ }^{10}$ A título de información sobre los datos a los que nos vamos a referir, señalaremos que se trata de informaciones obtenidas de manera directa, mediante consulta electrónica a 5 periódicos: El País, El Periódico de Cataluña, El Mundo, ABC y La Vanguardia. El período elegido se correspondía con los años completos de 2001 a 2011. La temática que interesaba se correspondía con "extranjeros inmigrantes" y con "educación” en cualquiera de los géneros periodísticos en que pudiera aparecer y en cualquiera de las secciones del periódico, excepción hecha de la sección de deportes. En términos metodológicos no interesaba tanto la supuesta representatividad estadística como las categorías temáticas que pudieran ofrecer claves interpretativas del modo en que los medios de comunicación estaban representando la presencia de población extranjera (inmigrante) en las escuelas. Finalmente, al objeto del presente trabajo y para focalizar la atención en torno a uno de los recursos periodísticos más usuales, hemos tenido en cuenta en el análisis, de manera prioritaria, el cuerpo del titular de la noticia-información en sus variantes de presentación: antetítulo-título / título / título-subtítulo(s) / antetítulo-título-subtítulo(s) / antetítulo-título-subtítulo(s)-entradilla / título-entradilla. Y ello, por tres razones: (1) porque los titulares suelen ser temáticos; esto es, enuncian o mencionan genéricamente los temas sobre los que trata el texto; (2) porque el titular tiene por función principal identificar unitariamente una secuencia del acontecer a que se refiere el texto informativo, de manera que el lector no necesita, en principio, leer el texto completo para saber de qué se habla en él; (3) porque el léxico, la sintaxis, el estilo, la retórica y la semántica de los titulares, junto con el sistema de referencias simbólicas y socioculturales a las que remite el tema de la noticia-información, ofrece elementos de análisis de suma pertinencia para comprender su intencionalidad de cara a la influencia perceptiva sobre el lector. 
Y vayamos, en primer lugar, a lo más obvio, mirando la definición que hace la RAE (Real Academia Española) sobre qué es una avalancha, para ver hasta qué punto esta metáfora contribuye a la "construcción del problema migratorio", en este caso en la escuela. Encontramos la siguiente definición: Alud. Gran masa [de nieve] que se derrumba [de los montes] con violencia y estrépito. Masa grande de una materia que se desprende por una vertiente, precipitándose por ella. Y vemos cómo además de referir magnitud, inmensidad, señala la forma en que la misma se acerca a otros tipos de materia: de manera violenta y precipitándose.

No menos problemático es el titular del ejemplo que sigue, y que evidencia lo que acabamos de decir, mostrar la llegada del alumnado de nacionalidad extranjera a las aulas en España como un fenómeno violento:

[Titular/Noticia] Explosión del alumnado inmigrante

[Primer párrafo/Cuerpo noticia] Cataluña vive una de las oleadas migratorias más importantes en los últimos años, fenómeno que las escuelas han notado sobremanera. (...)

[El País (Cataluña): 17/06/2005]

El término "explosión" usado en el titular de la noticia induce al lector a evaluar el incremento del alumnado (inmigrante) como un fenómeno descontrolado e inesperado cuyas consecuencias son imprevisibles y dañinas. Su efectividad en términos de definición del acontecimiento al que se refiere se ve potenciado y amplificado en el inicio del cuerpo de la noticia con el uso de figuras retóricas que remiten, igualmente, a una cantidad indefinida e imprecisa pero amenazante e impredecible (OLEADA) y que, además, señala el origen de las migraciones (mar/patera/África).

Es decir, una de las primeras estrategias discursivas detectadas en este proceso consiste en el convencimiento de la creencia de que una presencia del $10 \%{ }^{11}$ de población extranjera en el sistema educativo español es una "avalancha". Otra estrategia muy relacionada con la anterior, es precisamente la forma de narrar esa llegada, magnificando igualmente las dimensiones de la misma. Obsérvese en la siguiente noticia el tono con el que el antetítulo anuncia su contenido: la educación tiene un reto por encima del plural con el que se presentan sus desafíos que no es otro que el de la presencia de alumnado "inmigrante" que, por miles, llegan por sorpresa; es decir, sin previo aviso, de forma inesperada y, con toda certeza, intrusos ante los cuales la educación tiene que desplegar, en el mejor de los casos, sus mejores artes de cortesía no exenta de diplomacia puesto que de un reto se trata:

[Antetitulo] LOS RETOS DE LA EDUCACIÓN

[Titulo] Cinco mil alumnos por sorpresa

[Subtitulo] El 80\% de los estudiantes que se matriculan a mitad de curso son inmigrantes

[La Vanguardia: 13/06/2006]

${ }^{11}$ El porcentaje de alumnado de nacionalidad extranjera matriculado en enseñanzas de régimen general no universitarias para el curso 2010-2011 era de un 9,5 del total del alumnado (Datos obtenidos del Ministerio de Educación). 
De paso, la noticia desvela uno de los rasgos definidores de las migraciones que es su movilidad -la de las familias del alumnado escolarizado- para el que el sistema educativo (sus estructuras organizativas, docentes y curriculares) no está preparado. Una carencia de previsión sustentada en la creencia inconsciente o deliberada pero, en cualquier caso, insostenible, de que el fenómeno migratorio es un fenómeno pasajero y que no debe modificar las estructuras existentes de nuestro sistema escolar. El resultado es que un cambio coyuntural producido por la llegada no controlada de población escolar no esperada se convierte en un problema estructural del sistema de acogida porque dicho sistema no contempla la realidad de la población extranjera inmigrante ${ }^{12}$. Al ignorarla la convierte en problema cuando ésta se manifiesta haciendo valer el derecho constitucional a ser atendida.

Otra forma de contribuir a esta empresa es a través del abuso del recurso a las expresiones numéricas, las metáforas empleadas para hablar de cantidades y el énfasis puesto en las supuestas consecuencias de esos porcentajes. En efecto, el resultado de más de una década mostrando porcentajes, cantidades, números, cifras, estadísticas sobre población extranjera en las escuelas, en detrimento de otro tipo de información es, de nuevo, algo muy parecido a una avalancha (discursiva, mediática, pero con efectos sobre la configuración de opinión pública):

[Titular/Noticia] El número de alumnos extranjeros es 10 veces superior al de hace una década

[Primer párrafo/Cuerpo noticia] El alumnado extranjero de enseñanzas no universitarias creció el 14\% el curso pasado y se acercó a los 700.000 matriculados, la mayor parte de ellos en Primaria, según el último avance estadístico publicado por el Ministerio de Educación, Política Social y Deporte.

[El Mundo: 27/07/2008]

Vemos cómo se presentan los datos de forma que priman una interpretación amplificada del número real. En el caso anterior falta información para no tener que hacer un análisis un poco más detallado de cara a entender los porcentajes que se refieren. Dado que no se nos dice cual era el porcentaje de alumnado de nacionalidad extranjera ni hace 10 años ni en la fecha de que data la noticia, no podemos saber en cuántos puntos porcentuales ha crecido realmente la población de que se habla. Se nos queda en la mente ese $14 \%$, sin embargo ese dato es de crecimiento de un porcentaje de la población escolar, y no de proporción de la misma, que sin duda es mucho menor $^{13}$. Veamos otro ejemplo con consecuencias muy parecidas:

${ }^{12}$ Como hemos comentado en trabajos anteriores, es más preciso hablar de un proceso de visibilización de la población extranjera en las escuelas en España que de un proceso de incorporación repentino y masivo, dado que las estadísticas no recogían información sobre extranjería desde el inicio de la llegada de este alumnado, y no todas las regiones y centros comienzan a hacerlo al mismo tiempo.

${ }^{13}$ En el curso escolar 2007/2008 las estadísticas recogen que había 703.497 alumnos/as extranjeros matriculados. Esto supone un 9,4\% del total (Datos obtenidos del Ministerio de Educación). 


\section{[Antetitulo] LA VUELTA AL COLE}

[Titulo] La nueva Catalunya inicia el curso

[Subtitulo] Uno de cada ocho alumnos de los colegios e institutos catalanes es extranjero

[Entradilla] El alumnado de origen extranjero se ha multiplicado por cinco en seis años y suma más de 120.000 niños, como reflejo del aumento de la creciente inmigración

[La Vanguardia: 07/09/2006]

Nos servíamos de esta noticia para dar título a este apartado del capítulo, y ya hemos reflexionado sobre la misma. Existe una intención muy marcada por señalar y subrayar expresiones que denotan proporciones difíciles de traducir a medidas comprensibles para el ciudadano medio: "Uno de cada ocho alumnos": ¿son muchos? ¿son pocos? ¿en relación a qué y a cuánto?; operaciones aritméticas alarmantes “... se ha multiplicado por cinco en seis años ..." y una redundancia o ¿pleonasmo? que amplifica el efecto multiplicación “... aumento de la creciente inmigración”.

Por último, es importante mostrar las consecuencias de la presencia de la población extranjera en la escuela en España que son destacadas por la prensa, consecuencias que aparecen en plena concordancia con su descripción. En este sentido, sobresale una de ellas: la falta de recursos -humanos y materiales- "provocada" porque hay más estudiantes (extranjeros):

\section{[Antetitulo] EL DESASTRE DE LA EDUCACIÓN EN CATALUÑA(I)}

[Titulo] La falta de recursos obliga a muchos niños a hacer de traductores en aulas con inmigrantes

[Subtitulo] Un instituto de Santa Coloma tiene dos profesores para 70 niños recién llegados

[Entradilla] La masificación en las aulas y la desigual distribución de fondos para hacer frente a los nuevos retos educativos cobra su cara más drástica en los centros de algunas poblaciones. Santa Coloma de Gramenet está entre las más fustigadas.

[El Mundo: 27/10/2008]

Un alumnado cuya llegada y presencia es descrita como una avalancha que es mostrado como culpable del "desastre de la educación", al no haber suficiente profesorado y necesitar de los propios niños en calidad de traductores. Muy habitual es también relacionar la presencia de alumnado de nacionalidad extranjera con la saturación de infraestructuras escolares de acogida:

[Titular/Noticia] 21.000 alumnos comenzarán el curso en barracones

[Último párrafo/Cuerpo noticia] Reagrupación de inmigrantes. Claro que este curso empieza con una incertidumbre clave. Nadie sabe exactamente cuántos niños inmigrantes llegarán en enero a las escuelas catalanas por reagrupación familiar, consecuencia del último proceso de regularización. Ni cómo esto afec- 
tará a la demanda de aulas. Durante el curso 2004-2005, se matricularon en las escuelas catalanas 38.000 nuevos estudiantes, 22.000 de ellos de origen foráneo. [El Periódico de Cataluña: 06/09/2005]

El titular de la noticia no indica que la causa por la que 21.000 alumnos vayan a comenzar el curso en barracones sea la presencia de alumnado de nacionalidad extranjera (inmigrante). Pero el lector de este tipo de informaciones ha sido aleccionado para interpretar los datos negativos relacionados con insuficiencias de infraestructuras o con deficiencias organizativas al inicio de cada curso a partir de guiones y de modelos explicativos que se repiten en esas fechas. De modo que sólo tendrá que recorrer con la mirada el cuerpo de la noticia para encontrar en el último párrafo que la explicación a ese problema no es otro que la "reagrupación de inmigrantes" y la llegada de 22.000 escolares extranjeros de entre los 38.000 nuevos estudiantes.

\subsection{Instrucciones para construir un gueto}

De nuevo, un título irónico para describir unos análisis serios y rigurosos. La elección del mismo se debe a que, como hemos anunciado en más de una ocasión, hablar de guetos es una de las temáticas preferidas en los medios de comunicación en estos momentos en España ( $\mathrm{y}$ concretamente en la prensa) para informar sobre inmigración y escuela. Ya hemos analizado en otros trabajos las características que los especialistas en la materia enumeran como elementos que contribuyen a la formación de lo que se conoce como "gueto escolar" (Olmos, 2009; García Castaño et al., 2013). Baste con recordar aquí que uno de los argumentos más importantes es precisamente que el centro educativo en cuestión sea definido y visto por la población como gueto, independientemente de que tenga las características físicas y estructurales típicas de este tipo de centros (aislamiento, deterioro, abandono institucional...). Pues bien, la prensa analizada está haciendo un flaco favor a las escuelas con presencia de población extranjera (inmigrante) en este sentido, dado que se utiliza de manera libre y frecuente -entendemos que por el impacto mediático- dicho apelativo. Titulares como el que sigue pueblan los diarios españoles cada vez que se inicia el curso escolar:

\section{[Antetítulo] PARA EVITAR LA FORMACIÓN DE GUETOS}

[Titulo] El PSOE propone fijar un porcentaje máximo de alumnado inmigrante por colegio y distrito

[Subtitulo] La red pública escolariza al 78,6\% de los extranjeros y la concertada al $21,4 \%$

[Entradilla] Fijar un porcentaje máximo de alumnado inmigrante por centro y distrito escolar y destinar más recursos y profesores a los centros cuyo porcentaje de alumnos inmigrantes supere la media de inmigrantes de su zona. Estas son algunas de las propuestas que el PSM-PSOE quiere llevar a la Asamblea de Madrid ante el aumento del riesgo de creación de guetos por la excesiva concentración de alumnado inmigrante en los centros públicos, según indicó el portavoz de Educación del grupo socialista en el Parlamento regional, Adolfo Navarro.

[El Mundo (Madrid): 19/02/2006] 
El contenido de esta noticia advierte del "riesgo de creación de guetos" (normalmente el discurso es preventivo, no es que se constate que haya guetos sino que se teme que aparezcan) por la "excesiva concentración de alumnado inmigrante". $\mathrm{He}$ aquí un ejemplo de los más frecuentes en cuanto a lo que apuntábamos sobre el uso del calificativo de gueto libremente. La simple presencia -aunque sea significativa- de un conjunto de escolares que comparten nacionalidad y/o procedencia no es suficiente para calificar un espacio escolar en estos términos. Muy al contrario quizá lo prioritario es que esa concentración vaya asociada a situaciones de marginación social, exclusión, abandono (García Castaño et al., 2013). En la misma línea vemos el siguiente titular, también del diario El Mundo:

\section{[Antetitulo] A FONDO / LA SEGREGACION ESCOLAR}

[Titulo] El reto de frenar la proliferación de escuelas gueto

[Primer párrafo/Cuerpo noticia] La concentración de altos porcentajes de alumnos inmigrantes en colegios de determinados barrios catalanes es un fenómeno creciente que está derivando en una distribución desigual y poco equitativa de este colectivo estudiantil y fomentando la aparición de los primeros guetos escolares. El Síndic de Greuges, Rafael Ribó, alerta explícitamente de este proceso en su último informe remitido al Parlament. En él, además, indica que, de no aplicarse medidas correctoras efectivas, se puede producir una auténtica «segregación escolar». Algunos padres autóctonos ya se niegan a matricular a sus hijos en los centros con mayor índice de inmigrantes por miedo a que baje su rendimiento escolar, y los colegios afectados temen que se les acabe estigmatizando.

[El Mundo: 10/06/2007]

Donde se añade otra de las palabras asociadas más habitualmente a la de gueto: segregación; y que añade connotaciones de carácter más negativo a la descripción de los procesos de escolarización de este alumnado, dado que alude a la separación entre grupos a partir de jerarquías, relaciones de poder y acceso desigual a los recursos. Además, vemos cómo también se incluyen supuestos efectos perversos de esos procesos de guetización, como es el "miedo al descenso del rendimiento escolar" y el "consiguientemente justificado" -parece sugerirse- abandono de autóctonos de las escuelas con alto porcentaje de alumnado de nacionalidad extranjera.

El segundo paso seguido por la prensa analizada en su particular contribución de fomentar la creencia entre la opinión pública de que la presencia de alumnado de nacionalidad extranjera (inmigrante) en las escuelas en España promueve el surgimiento de guetos escolares, es apoyar sus argumentos en ciertas opiniones de expertos:

[Titulo] El Consejo de Europa critica las 'aulas gueto' españolas

[Subtitulo] El informe sobre la situación de España destaca que no hay registros de violencia racista

[Cuerpo noticia] La Comisión Europea contra el Racismo y la Intolerancia (ECRI por sus siglas en inglés) ha hecho público su cuarto informe sobre España. En él destacan dos críticas: el irregular reparto de los alumnos de colectivos más 
desfavorecidos, lo que da lugar a las aulas gueto, y que no hay registros oficiales de qué delitos, sobre todo, agresiones, tienen un agravante de racismo. El trabajo pide que haya un reparto equitativo de niños inmigrantes y gitanos por las escuelas. El estudio también indica que hay "un creciente número de movimientos neonazis y el racismo aumenta en Internet". "Las autoridades deben vigilar de cerca esta situación e iniciar acciones penales cuando sea necesario", señala el informe.

[El Pais: 08/02/2011]

Y nada mejor para ello que las propias instancias europeas sean quienes hablen de "aulas gueto". Podríamos pensar que con esta expresión el informe reseñado en la unidad informativa se está refiriendo a los EBE (Espacios de Bienvenida Educativos) catalanes, dispositivos que se implantaron a modo de "aulas puente" y donde se escolarizó durante un tiempo a alumnado inmigrante recién llegado de manera segregada al resto del alumnado. Esta actuación, puesta en marcha con la excusa de acelerar el proceso de integración de estos escolares, sí suponía un verdadero espacio educativo segregador, y con un poder enorme para crear y difundir la idea de que la inmigración -el alumnado de nacionalidad extranjera- es un serio problema que ha de ser controlado, separado y aislado del resto del sistema educativo. Pero nada más lejos de la realidad. Si leemos la información completa vemos cómo el informe se refiere a la distribución "irregular" del alumnado.

Finalmente, nos gustaría mostrar cómo en este proceso de creación de alarma social son muy determinantes las imágenes que, en ocasiones, ilustran este tipo de noticias. Veamos algunos ejemplos encontrados que destacan una "asociación forzada". Forzada en el sentido de que, en ocasiones, como en la siguiente, la imagen ni siquiera pertenece a la unidad informativa en cuestión.

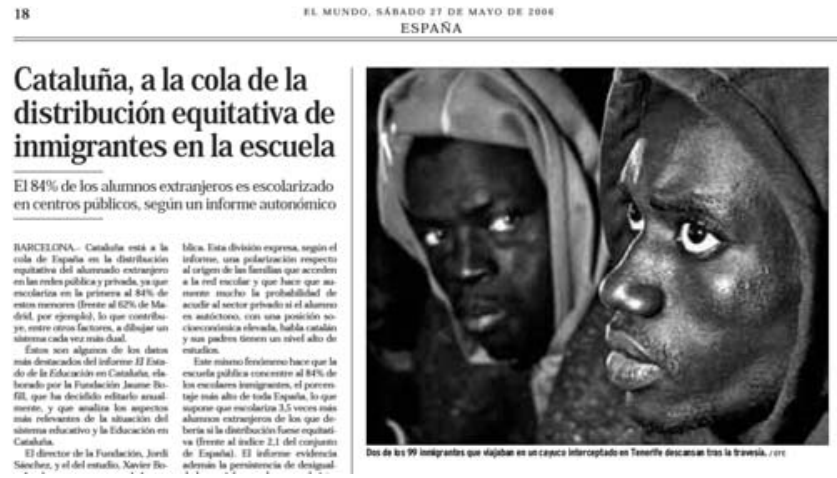

Foto 1. Cataluña, a la cola de la distribución equitativa de inmigrantes en la escuela.

Fuente: Periódico El Mundo, 27 de mayo de 2006

En este caso, se ha elegido situar de manera sospechosamente próxima dos noticias que hacen referencia a asuntos diferentes. El titular de la imagen de la Foto 1 es: "Sólo se ha expulsado al 6\% de los 'sin papeles' llegados a Canarias", pero las personas encargadas de maquetar la página debieron pensar que una fotografía en primer 
plano de dos personas que acaban de llegar a las costas canarias en cayuco/patera podía ilustrar igualmente bien una información relativa a los procesos de escolarización del alumnado de nacionalidad extranjera. De otra forma no se entendería -o sila distribución espacial que se hace de textos e imagen. Pero es que, en ocasiones, estas interpretaciones que como analistas sociales realizamos, son mostradas de manera abierta por la prensa. Véase la siguiente foto y, sobre todo, el pie de la misma.

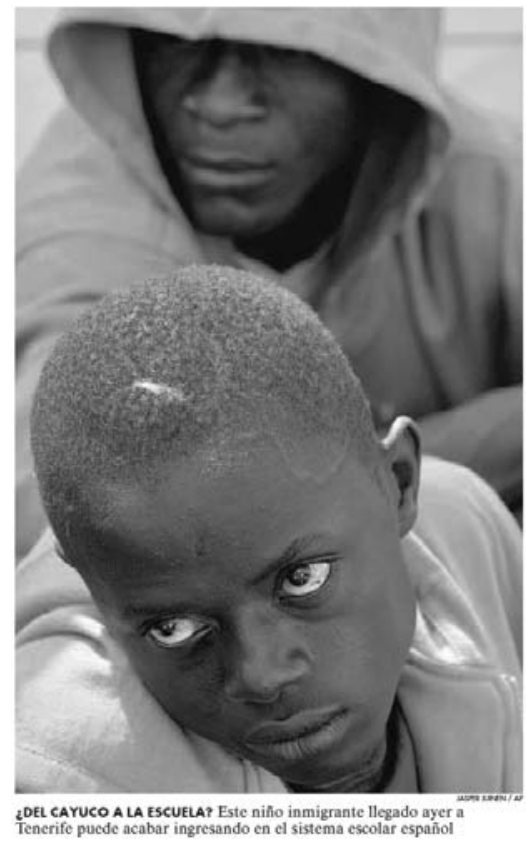

Foto 2. ¿DEL CAYUCO A LA ESCUELA? Este niño inmigrante llegado ayer a Tenerife podría acabar ingresando en el sistema educativo escolar español.

Fuente: Periódico La Vanguardia, 7 de septiembre de 2006.

Pertenece a una noticia que ya hemos comentado anteriormente (LA VUELTA AL COLE. La nueva Catalunya inicia el curso. Uno de cada ocho alumnos de los colegios e institutos catalanes es extranjero. El alumnado de origen extranjero se ha multiplicado por cinco en seis años y suma más de 120.000 niños, como reflejo del aumento de la creciente inmigración [La Vanguardia: 07/09/2006]) y nos muestra abiertamente esa asociación de imágenes dramáticas, que nada tienen que ver con la escuela ni con los procesos de escolarización del alumnado de nacionalidad extranjera (inmigrante).

Pero reflexionando sobre el asunto ¿cómo podríamos ilustrar una noticia que habla de guetos escolares en España? En realidad es difícil contestar a esta pregunta. Quizá se podría mostrar el deterioro del mobiliario, el aislamiento del centro educativo o las condiciones en que trabaja el profesorado... realmente reconocemos que es una labor complicada. Y más complicada aún si -como apuntamos- en la mayoría de las ocasiones se habla de los miedos al surgimiento de guetos y no de los guetos que realmente existen; lo que impide que se disponga de imágenes sobre ellos. Con 
independencia de estas dificultades, hemos observado, a la luz de algunos hallazgos, que puede haber una idea subyacente acerca de cómo podría ser un gueto escolar en España. Veamos las Fotos 3 y 4.

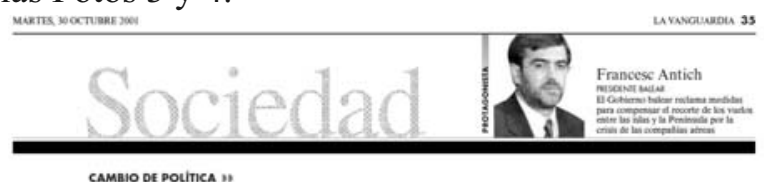

Un decreto contra los guetos escolares

Los centros concertados deberán acoger más inmigrantes en algunas zonas

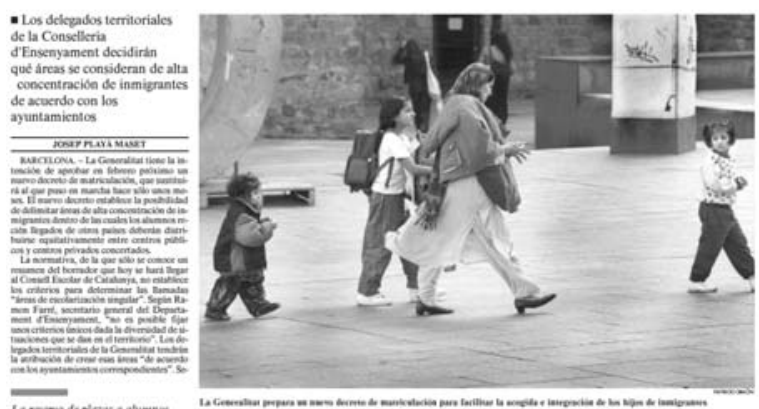

Foto 3. Un decreto contra los guetos escolares. Los centros concertados deberán acoger más inmigrantes en algunas zonas. Fuente: Periódico La Vanguardia, 30 de octubre de 2008 .

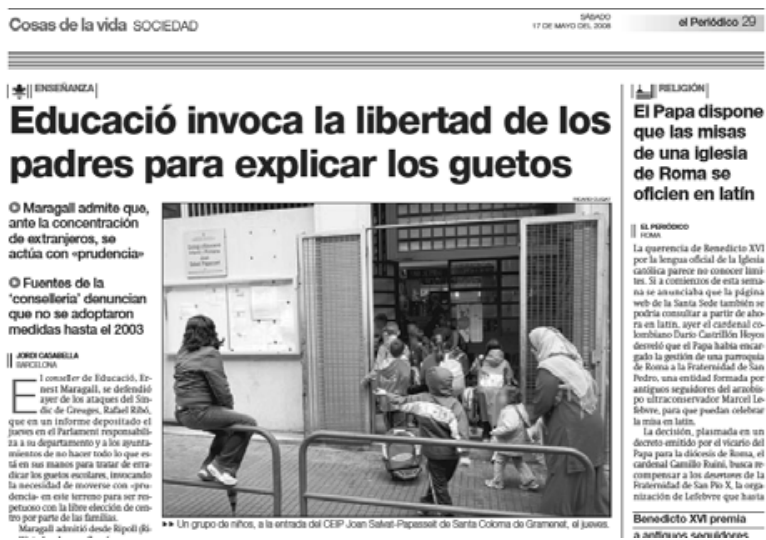

Foto 4. Educación invoca la libertad de los padres para explicar los guetos.

Fuente: Periódico El Periódico, 17 de mayo de 2008.

En ambas fotografías aparece el velo islámico, elemento visual tremendamente atractivo para los medios de comunicación. ¿Podríamos pensar entonces que esos posibles guetos que pueden estar surgiendo pudieran estar definiéndose por la presencia de alumnas y madres de alumnas que pueden vestir velo islámico? No tenemos respuesta a esta pregunta. No obstante, si tenemos en cuenta que se está hablando del 
"gueto escolar" (sea lo que sea y lo que se entienda por ello), algo que provoca malestar, miedo y angustia y ya tenemos algo que provoca esas sensaciones: "el velo islámico en la escuela"... ¿por qué no asociarlo y acabar con el problema de tener que imaginar una hipotética situación futura?

\subsection{Receta para culpar al inmigrante del fracaso escolar de la escuela en España} Continuamos con la ironía. El primer ingrediente de esta receta es describir al alumnado de nacionalidad extranjera como un alumnado con problemas de aprendizaje en la escuela:

[Titulo] La mitad de los 35.000 escolares inmigrantes tiene problemas de aprendizaje e integración

[Subtitulo] Un estudio revela que un número 'indeterminado' de menores de 16 años no va al colegio

[Cuerpo noticia]. La mitad de los 35.000 inmigrantes que había escolarizados el curso pasado en la región presentaba problemas de aprendizaje o de integración. Es una de las principales conclusiones de un informe elaborado por la Universidad Complutense sobre la atención a estos nuevos madrileños en los centros escolares.

[El Pais: 15/010/2001]

Una imagen homogeneizadora que no entra en matices y que concluye que este alumnado no consigue el éxito escolar obviando, en la mayoría de las ocasiones, que el proceso de aprendizaje no es una cuestión unilineal y que recaiga exclusivamente en el alumnado. En la misma línea que la noticia anterior, encontramos la siguiente:

[Titulo] Varón, 15 años e inmigrante: perfil de fracaso escolar en España

[Subtitulo] Un estudio elaborado por la Fundación «La Caixa»

[Cuerpo noticia]. Nueve de cada diez alumnos que no acaban la enseñanza obligatoria han repetido curso alguna vez y han faltado reiteradamente a clase. Un sistema poco atractivo y retrasos de curso desde primaria culminan, según el estudio "Fracaso y abandono escolar en España", elaborado por la Fundación "La Caixa", en fracaso escolar. [...] Además, el informe elabora el perfil del alumno con fracaso escolar: varón, 15 años, de origen inmigrante, estudia en un centro público y es hijo de un trabajador no cualificado.

[ABC: 8/07/2010]

En ella observamos cómo si no llegamos hasta el final de la unidad informativa (se trata de una unidad extensa de ocho párrafos) y nos quedamos solo en el titular, no advertimos que la investigación en la que se basa el periodista para elaborar su información añade detalles más reveladores y menos reduccionistas. En el titular se nos dice que el perfil del fracaso escolar en España es la de un "varón de 15 años inmigrante". Sin embargo, descubrimos (en el último párrafo de la noticia) que no es inmigrante sino "de origen inmigrante". El matiz es importante y mucho, porque ¿qué es ser de origen inmigrante?. Podemos entender que la persona en cuestión no ha emi- 
grado nunca -lo hizo alguno de sus padres- y que posiblemente haya nacido en España, con lo cual es nuevamente probable que sea español. Entonces ¿por qué hablar de fracaso escolar e inmigración? ¿por qué no hablar de fracaso escolar sin más? De nuevo, esta asociación imprecisa, inexacta y errónea contribuye a la elaboración del cóctel de "la inmigración como problema".

Un segundo ingrediente lo encontramos en la relación entre los malos resultados obtenidos en general por el sistema educativo español y el fracaso escolar atribuido al alumnado de nacionalidad extranjera:

[Título] Tras las causas del fracaso escolar

[Subtítulo] La media de éxito académico desciende con la llegada masiva de inmigrantes

[La Vanguardia: $15 / 11 / 2005]$

Este planteamiento sostiene que allí donde hay extranjeros (inmigrantes) el ritmo de aprendizaje es más lento y el alumnado autóctono recibe menor atención que la que obtendría sin su presencia, lo que los convierte en causa del incremento del fracaso escolar. Esta forma de presentar los hechos presupone que unos son plenos sujetos de derecho a la hora de recibir educación y otros no lo son y están tomando algo que no les pertenece: el tiempo de los docentes (españoles).

En suma, el género de noticia, el que domina absolutamente en todas las informaciones recogidas, no plantea en sus titulares la realidad de las estructuras institucionales escolares como problematizadoras. No alcanza a entrever que el acceso de población extranjera a cualquier servicio público implica cambios importantes en su organización. Tales cambios son a menudo fuente de conflictos y de tensiones atribuibles en exclusiva a la llegada de población extranjera cuando, en realidad, son fruto de unas limitaciones existentes con anterioridad a dicha llegada y que ésta no hace más que evidenciar.

\section{Reflexiones finales}

En España, una nueva dimensión de la diferencia-diversidad está aflorando, cada vez más visible y mediática: se manifiesta por las condiciones de acogida y de integración de los inmigrantes extranjeros y, consecuentemente, por las políticas desarrolladas a tal efecto en los ámbitos educativo, sanitario, laboral o de vivienda. Se trata de una dimensión que procura gestionar la diversidad representada por los inmigrantes. Una diversidad directamente proporcional a cada una de las poblaciones que llegan; con sus tradiciones, su religión, su lengua y sus normas de relación y de convivencia. El reto para la sociedad en España está en conseguir mecanismos de acomodación y de gestión adecuados a dicha diversidad. Fundamentalmente, mecanismos que impidan que la diversidad se convierta en desigualdad de derechos y deberes de los ciudadanos, sea cual sea su origen étnico o territorial.

La sociedad en España, y muy especialmente los medios de comunicación, tiene varias opciones: o recrearse en el drama de los que pierden su vida en el intento de llegar al país y acentuar los aspectos "problemáticos" de la inmigración -invasión de "nuestro" territorio, inseguridad y delincuencia (mafias, tráfico de drogas, prostitución, 
marginación), competencia laboral, conflictos de convivencia, masificación y colapso de servicios públicos como la sanidad o la educación, invasión de los espacios públicos como calles, plazas, barrios, etc.-, o, por el contrario, presentar las ventajas de la inmigración desde el punto de vista demográfico, económico y cultural y asumir que somos, y hemos sido siempre, una sociedad diversa, y que la presencia de inmigrantes no hace sino añadir mayor diversidad. Nuestra experiencia investigadora en el campo nos dice, como hemos mostrado a lo largo de todo el texto, que lo primero es mucho más frecuente que lo segundo.

Hasta fecha reciente, la presencia de menores extranjeros procedentes de la inmigración de sus padres -en tanto que representantes de una diversidad fácilmente gestionable desde principios de asimilación homogeneizante- no ha sido problemática, por lo que la posibilidad de aparecer en titulares en los medios de comunicación ha sido muy escasa. Aunque en la actualidad sigue siendo un tipo de información numéricamente minoritaria frente a otros tipos, su número está aumentando en progresión geométrica. Por ello, resulta pertinente seguir no tanto dicha progresión como el eco que ésta tiene en los medios de comunicación y su consecuente impacto en la opinión pública.

Puesto que la política española en materia de inmigración ha tenido que cambiar forzosamente, y en un plazo relativamente corto, de las estrictas medidas de control y de contención de los flujos migratorios a planteamientos de acogida y de integración de dichos flujos, la prensa deberá reflejar el cambio de dichos planteamientos. La escuela, y el mandato constitucional de escolarización de niños y niñas procedentes de otros países y tradiciones culturales en igualdad de condiciones y de oportunidades que los que tienen padres de nacionalidad española es, sin duda, un espacio privilegiado en cuyo terreno se puede observar y valorar el alcance de las llamadas políticas de acogida y de integración.

Esta es la propuesta de trabajo que hemos tratado de presentar: el análisis del discurso mediático presente en la prensa en España que evidencia su carácter problematizador, y que se ve reflejado en las informaciones que tratan de la incorporación al sistema educativo (llegada, acogida y atención) de niños y adolescentes cuyos padres son, o han sido, extranjeros obligados por circunstancias económicas a instalarse en España.

Más que concluir, señalaremos un par de ideas que nos parecen importantes para incorporar al universo teórico sobre la integración en las escuelas y al eco que ésta tiene en la prensa:

- (a) aunque la presencia de alumnado de nacionalidad extranjera en la escuela no ha causado hasta ahora ningún problema de especial gravedad (ni siquiera en los casos en los que ha habido conflicto por el uso del hiyab), puede haber agudizado los que ésta ya tenía con o sin dicho alumnado. Esta cuestión parece que no esté en los guiones de los titulares de prensa, bien porque no se sepa ver, bien porque interesa reproducir y mantener un tono conflictivo y problemático respecto de la extranjería y la inmigración.

- (b) es preciso que tanto los extranjeros (inmigrantes) y sus comunidades como los centros escolares -también los ayuntamientos, las comunidades de vecinos, las asociaciones de padres, etc.- se impliquen en proyectos compartidos que les 
permitan establecer interrelaciones en un nivel básico de igualdad, y que permita ir forjando síntesis culturales creativas, terceras culturas, que expresen estrategias de acomodación y readaptación recíproca, y que impliquen, además, a los medios de comunicación locales, regionales y nacionales, para que cesen en la tarea de adaptar la realidad a sus discursos.

\section{Referencias bibliográficas}

BAÑÓN, Antonio Miguel (2007): "Responsabilidad su representación en el discurso periodístico sobre la inmigración”, en IGARTUA, Juan José y MUÑIZ, Carlos (eds.): Medios de comunicación, inmigración y sociedad. Salamanca, Ediciones Universidad de Salamanca, pp.61-88.

CASERO, Andreu (2005): “Alteridad, identidad y representación mediática: la figura del inmigrante en la prensa española”. Signo y pensamiento, $\mathrm{n}^{\circ}$ 46, pp.138-151.

CASERO, Andreu (2007): "Ejes discursivos en la construcción mediática de la identidad de los inmigrantes", en BAÑÓN, Antonio Miguel (ed.): Discurso periodistico y procesos migratorios. Donostia-San Sebastián, Tercera Prensa-Hirugarren Prentsa, pp.139-160.

GARCÍA CASTAÑO, Francisco Javier; OLMOS ALCARAZ, Antonia; y RUBIO GÓMEZ, María (2013): "La diversidad que nos enriquece y la diferencia que nos desiguala. Discursos contradictorios sobre la presencia de escolares extranjeros en el sistema educativo", en Granados, Antolín (ed.): La representación de las migraciones en los medios de comunicación. Madrid: Trotta, pp. 195-219.

GRANADOS MARTÍNEZ, Antolín (1998): La imagen del inmigrante extranjero en la prensa española: ABC, Diario 16, El Mundo y El País (1985-1992).Tesis Doctoral, Universidad de Granada.

GRANADOS MARTÍNEZ, Antolín (2006): "Medios de comunicación, opinión y diversidad (social y cultural). Reflexiones en torno al fenómeno migratorio", en LARIO BASTIDA, Manuel (coord.): Medios de comunicación e inmigración. Murcia, CAM-Obra Social, pp. 59-83.

GRANGE, Juliette (2005): "Que veut dire intégration? Histoire d'une notion". En VICENT FERRY, Piero-D Galloro y NOIRIEL, Gérard (dir.): 20 ans de discours sur l'intégration. Paris, L'Harmattan, pp. 41-47.

IGARTUA, Juan José y MUÑIZ, Carlos (Eds., 2007): Medios de comunicación, inmigración y sociedad. Salamanca, Ediciones Universidad de Salamanca.

LARIO BASTIDA, Manuel (Coord., 2006): Medios de comunicación e inmigración. Murcia, CAM-Obra Social.

LORITE, Nicolás (2004): Tratamiento informativo de la inmigración en España: 2002. Madrid, Imserso - Ministerio de Trabajo y Asuntos Sociales.

MARTÍNEZ CHICÓN, Raquel (2005): Inmigración extranjera y trabajo. Jaén, Consejo Económico y Social. 
OLMOS ALCARAZ, Antonia (2009): La población inmigrante extranjera y la construcción de la diferencia. Discursos de alteridad en el sistema educativo andaluz. Tesis Doctoral, Universidad de Granada.

RETIS, Jessica (2006): El discurso público sobre la inmigración extracomunitaria en España. Análisis de la construcción de las imágenes de los inmigrantes latinoamericanos en la prensa de referencia. Tesis Doctoral, Universidad Complutense de Madrid.

SANTAMARÍA, Enrique (2002): "Inmigración y barbarie. La construcción social y política del inmigrante como amenaza". Papers, ${ }^{\circ} 66$, pp. 51-58.

WALSH, Catherine (2010): "Estudios (inter)culturales en clave de-colonial". Tábula Rasa, $\mathrm{n}^{\mathrm{O}}$ 12, pp. 209-227. 